\title{
COMPUTER MODELING OF INDICATORS OF AN ESTIMATION OF EFFECTIVENCY OF INVESTMENT PROJECTS
}

\section{КОМП'ЮТЕРНЕ МОДЕЛЮВАННЯ ПОКАЗНИКІВ ОЦІНКИ ЕФЕКТИВНОСТІ ІНВЕСТИЦІЙНИХ ПРОЕКТІВ}

\author{
V.B.Udolatiy ${ }^{1}$ assistant, A.E. Udolatiy $^{2}$, captain training manager \\ В.Б. Удолатій ${ }^{1}$, асистент, А.Є.У долатій ${ }^{2}$, капітан-наставник \\ ${ }^{I}$ National University «Odessa Maritime Academy», Ukraine \\ ${ }^{2}$ MSC Crewing Services, Odessa, Ukraine
}

\begin{abstract}
Great importance is attached to the effective use of financial means in maritime transport. In this article, we will talk about mathematical modeling of optimal management of investment projects. Consider using the Matlab / Simulink software package to optimize financial management projects for shipping companies. The Matlab / Simulink complex is designed for the development and analysis of engineering applications. It can also be used to model and analyze the dynamics of economic and financial forecasts. Simulink is an application to Matlab and is an interactive tool for visual design and analysis of dynamic systems.

In the article one of the tasks of financial management is considered computer modeling of indicators of efficiency evaluation of investment projects.

Investment projects are characterized, as a rule, by a long interval of realization. Therefore, there is a problem of bringing cash flows (current or forecasted in the future) to monetary units of a certain period of time. In this case, the discounted value method is used, the essence of which is determined by the procedure for calculating compound interest.

For a quantitative analysis of the results of investment projects, the net present value method (Net Present Value-NPV) and the Profitability Index (PI) method are widely used based on the discount calculations of income and expenses associated with the project implementation and reduced to a certain point in time (usually to the beginning of the project).

As an example, consider the algorithm for calculating in the Matlab / Simulink environment the indicator of the investment project of the shipping company associated with the acquisition of a new vessel.

The article shows a model made up of sections of the Simulink library that implements the calculation of the Present Value indicator. The operation of the S_PV model is controlled from the file program (Script M-Files) of the Matlab package.

This article analyzes the possibility of using the interactive visual design tool Simulink to analyze the dynamics of economic and financial forecasts. The resulted results testify to expediency of application of program complex Matlab / Simulink for optimization of projects of financial management of the shipping companies.
\end{abstract}


Keywords: investment project, model, software complex Matlab / Simulink.

\section{Постановка проблеми в загальному вигляді та її зв'язок 3 важливими науковими та практичними завданнями}

Для розвитку морського транспорту потрібні значні інвестиційні ресурси. Оптимальне управління інвестиційними процесами з використанням засобів математичного моделювання $є$ актуальним завданням. Matlab - універсальний засіб вирішення широкого кола завдань в різних предметних областях. Simulink $\epsilon$ додатком до Matlab i являє собою інтерактивний інструмент візуального проектування і аналізу динамічних систем. Simulink повністю інтегрований 3 пакетом MATLAB, що забезпечує швидкий доступ до інструментів аналізу i проектування останнього[1]. У той же час Simulink є самостійним інструментом в тому сенсі, що при роботі з ним не обов'язково знати сам Matlab. Ці переваги роблять Simulink найбільш популярним інструментом для проектування i аналізу систем управління, цифрової обробки даних i iнших задач моделювання.

Аналіз останніх досягнень та публікацій, в яких розпочато розв 'язування даної проблеми та висвітлювання нерозв`язаних раніше частин загальної проблеми

Комплекс Matlab/Simulink призначений для розробки i аналізу інженерних додатків. Він може бути також використаний для моделювання та аналізу динаміки економічних і фінансових прогнозів [2]. Інвестиційні проекти характеризуються, як правило, тривалим інтервалом реалізації. Тому виникає проблема приведення потоків грошових коштів (поточних або прогнозованих в майбутньому) до грошових одиниць певного періоду часу. У цьому випадку використовується метод приведеної вартості (метод дисконтування), суть якого визначається порядком нарахування складних відсотків.

Для кількісного аналізу результатів інвестиційних проектів широке застосування отримали метод чистої теперішньої вартості (Net Present Value NPV) і метод розрахунку індексу прибутковості (Profitability index - PI), що базуються на дисконтних обчисленнях доходів i розходів, пов'язаних 3 реалізацією проекту і приведених до деякого моменту часу (зазвичай до початку проекту). Сучасна вартість PV (Present Value) очікуваних в майбутньому потоків грошових коштів визначається за виразом [2]:

$$
\sum_{t=1}^{T} P V\left(C F_{t}\right)=\sum_{k=1}^{T} \frac{C F_{t}}{\left(1+\frac{p}{100}\right)^{t}},
$$

де (Cash Flow) - потік грошових коштів протягом року $t$ при реалізації проекту; $p$ - процентна ставка; $T$ - період реалізації проекту. Чиста сучасна вартість $N P V$ і індекс прибутковості PI обчислюються за формулами [2] та [3]: 


$$
N P V=\sum_{t=1}^{T} P V\left(C F_{t}\right)-I_{0} . \quad \text { (2) } \quad P I=\frac{1}{I_{0}} \sum_{t=1}^{T} P V\left(C F_{t}\right) .
$$

$\mathrm{I}_{0}$ - сума одноразових інвестицій у проект.

\section{Формулювання мети статі (постановка задачі)}

У статті розглядається одне із завдань фінансового менеджменту комп'ютерне моделювання показників оцінки ефективності інвестиційних проектів. Як приклад розглянемо алгоритм розрахунку в середовищі Matlab/Simulink показника $N P V$ інвестиційного проекту судноплавної компанії, пов'язаного з придбанням нового судна.

\section{Виклад матеріалу дослідження з обгрунтуванням отриманих наукових результатів}

Судно купується за таких умов: вартість судна $=3$ млн. дол. Період експлуатації судна 3 роки; потоки грошових коштів - 2 млн. дол. (1-й рік експлуатації судна); 1 млн. дол. (2-й і 3-й роки експлуатації судна); процентна ставка $10 \%$. Такий варіант був розглянутий в роботі [3] і в результаті розрахунку було отримано $-N P V=0,3959$ млн. дол. $\approx 0,4$ млн. дол..

На рис. 1 зображена модель $S \_P V$ ( $S$-модель), на якій наведено блоки розділів бібліотеки Simulink, необхідні для реалізації обчислень показника за формулою (1).

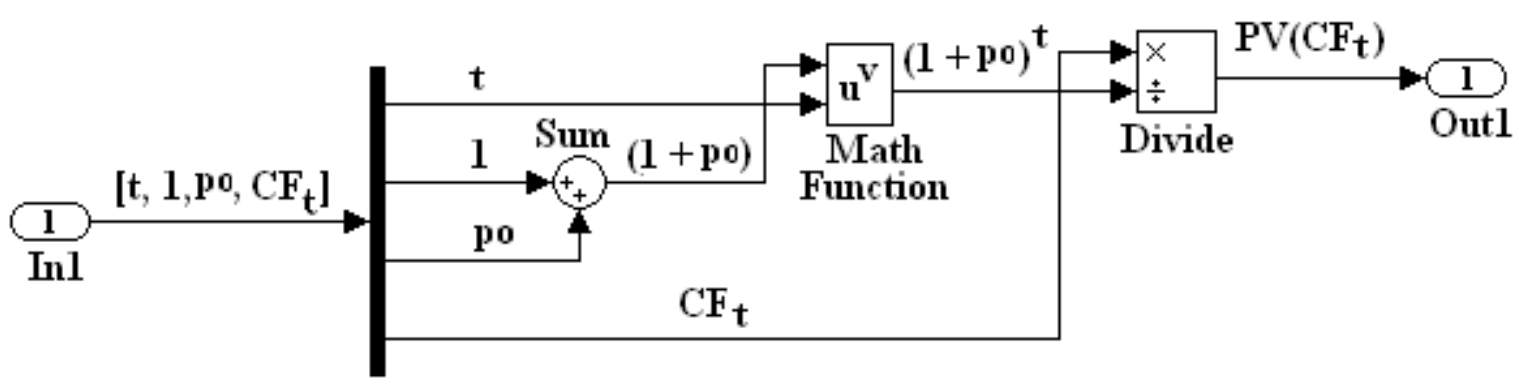

Demux

Puc. 1. Модель S_PV, щуо реалізує обчислення показника $P V\left(C F_{t}\right)$

Слід зазначити, що робочий простір (Workspace) Matlab завжди доступний для $S$-моделі і може бути використаний для обміну даними, організації питань щодо функціонування моделі і для візуалізації отриманої інформації [4]. Перед виконанням розрахунків слід встановити параметри моделі $S \_P V$. Для цього у вікні моделі необхідно виконати команди Simulation $\rightarrow$ Configuration Parameters. В однойменному вікні вибрати вкладку Solver. В поле Type вибрати Fixed-Step; в поле Solver вибрати discrete (no continuous stats). В поле Fixed-Step size набрати 0.2. Інші параметри залишити без зміни. Вибрати вкладку Data Input / Export. Активувати поле Input, встановивши відповідний чек-боксУ. В поле Format вибрати Array. Інші параметри залишити без зміни. Натиснути кнопку Apply, потім кнопку $O K$.

Характеристика блоків моделі $S \_P V$. 
Блок In1 призначений для зчитування сигналів з робочої області в модель. Розмірність вхідного сигналу визначається автоматично. В даному випадку вхідний сигнал формується в робочому просторі Matlab i представляє вектор, що складається з чотирьох елементів: $u=\left[t, 1, p o, C F_{t}\right]$, де $p o=p / 100$.

Блок Deтих розділяе вхідний векторний сигнал на окремі. Кількість виходів 4. Інші параметри прийняті за замовчуванням. Блок Sum виконує обчислення суми поточних сигналів. Параметри прийняті за замовчуванням.

Блок Math Function виконує обчислення заданої математичної функції, що реалізує зведення значення першого вхідного сигналу до рівня значення другого вхідного сигналу. Для реалізації цієї функції параметр Function слід вибрати рівним pow. Інші параметри прийняті за замовчуванням.

Блок Divide виконує ділення величини першого вхідного сигналу на величину другого вхідного сигналу. Параметри прийняті за замовчуванням.

Блок Out1 призначений для створення вихідного порту для моделі, за допомогою якого в даному випадку в робочому просторі Matlab можна використовувати значення показника. Параметри прийняті за замовчуванням. Блоки $S \_P V$ моделі пов'язані сполучними лініями, над якими розташовані ідентифікатори переданих сигналів. Інших пояснень модель $S \_P V$ не вимагає.

Управління роботою моделі $S \_P V$ здійснюється з файл-програми (Script MFiles) Matlab. Нижче наведено код програми $S M F \_P V$.

$\%$ Код програми SMF_PV

path(path,'C:ModEkonlfile_mdl') \% шлях до папки з програмами open_system('S_PV') \% відкриття моделі $S \_P V$

$\%$ початкові дані

$\mathrm{i} 0=3$;

$\mathrm{p}=0: 2: 20$;

$\mathrm{j}=0$;

for po=0:0.02:0.20 \% цикл по процентній ставиі

$\mathrm{j}=\mathrm{j}+1 ; \quad \%$ допоміжнийлічильник циклу

for $\mathrm{t}=1: 3 \%$ иикл по роках інвестиційного проекту

switch $\mathrm{t}$

case 1

$\mathrm{u}=[\mathrm{t}, 1, \mathrm{po}, 2] ; \%$ вектор початкових даних для моделі

$\operatorname{sim}\left(\right.$ 'S_PV') \% запуск моделі $S_{-} P V$ на виконання

$\operatorname{pv}(1)=\operatorname{yout}(1)$;

case 2

$\mathrm{u}=[\mathrm{t}, 1, \mathrm{po}, 1] ; \%$ вектор початкових даних для моделі

sim('S_PV') \% запуск моделі $S_{-} P V$ на виконання

$\operatorname{pv}(2)=\operatorname{yout}(1)$;

case 3

$\mathrm{u}=\left[\mathrm{t}, 1, \mathrm{p}^{\mathrm{o}}, 1\right]$; \% вектор початкових даних для моделі

$\operatorname{sim}\left(' S \_P V '\right) \quad \%$ запуск моделі $S_{-} P V$ на виконання

$\operatorname{pv}(3)=\operatorname{yout}(1)$;

end \% кінець оператора switch 
end \% кінецьь цุиклу по роках

$\operatorname{spv}(j)=p v(1)+p v(2)+p v(3)$;

$\%$ обчислення показника NPV

$\operatorname{npv}(\mathrm{j})=\operatorname{spv}(\mathrm{j})-\mathrm{i} 0$;

\% обчислення показника PI

$\operatorname{pi}(\mathrm{j})=\operatorname{spv}(\mathrm{j}) / \mathrm{i} 0$;

end \% кінець цุиклу по процентній ставці

plot(p,npv,'k'), grid \% побудова графіка NPV (p)

title(' Графік показника NPV')

xlabel('Відсоткова ставка p (\%)') \% nidnис осі $X$

ylabel('Показник NPV (млн. дол.)') \% niдnис осі $Y$

figure(2)

plot(p,pi,'k'), grid \% побудова графіка $P I(p)$

title(' Графік показника PI ')

xlabel('Відсоткова ставка p (\%)') \% підпис осі $X$

ylabel('Показник PI') \% nidnuс осі $Y$

$\%$ Визначення показника IRR

syms x \% необов'язковий оператор (визначає символьні функиіі)

$\mathrm{x}=0: 2: 20$

$\mathrm{f}=\operatorname{solve}\left('-3+2 * \mathrm{x}+1 * \mathrm{x}^{\wedge} 2+1 * \mathrm{x}^{\wedge} 33^{\prime}, \mathrm{x}^{\prime}\right)$;

$\mathrm{f} \_\mathrm{x} 0=\mathrm{vpa}(\mathrm{f}, 4) ; \%$ символьна функція, щзо виводить на екран дисплея чотири числа коріня рівняння $f(x)=0$

irr=vpa $\left(\left(\left(1 / f \_x 0(1)\right)-1\right), 4\right)$

\% перевірка рівності нулю показника NPV при знайденому показнику IRR

$\mathrm{npv}=\operatorname{round}\left(-3+2 /(1+\mathrm{irr})+1 /(1+\mathrm{irr})^{\wedge} 2+1 /(1+\mathrm{irr})^{\wedge} 3\right)$

Код програми $S M F_{-} P V$ забезпечений докладними коментарями і інших пояснень не потребує. На рис. 2 і 3 наведені графіки показників $N P V$ i $P I$ відповідно в залежності від відсоткової ставки, обчислені за формулами (2) i (3). 3 ростом процентної ставки показники $N P V$ і $P I$ монотонно зменшуються. Як видно з рис. 2, при $10 \%$ показник $N P V \approx 0,4$ млн. дол. (збігається 3 результатом, наведеним в роботі [3]).

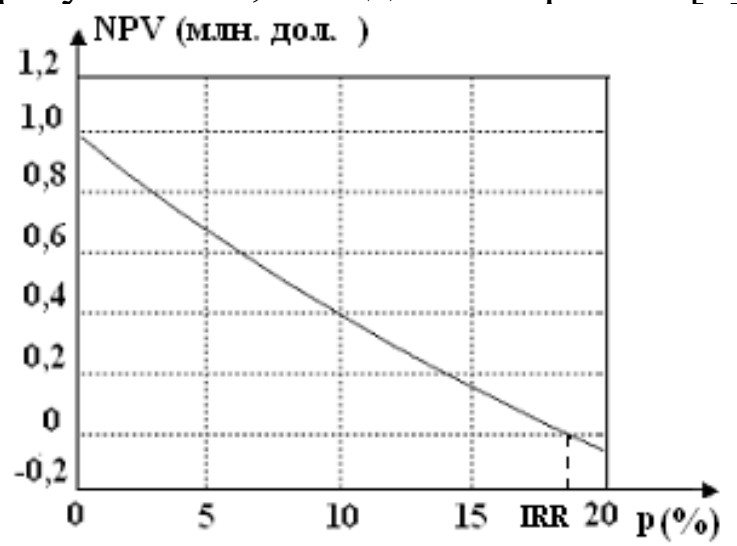

Рис. 2. Графік показника NPV

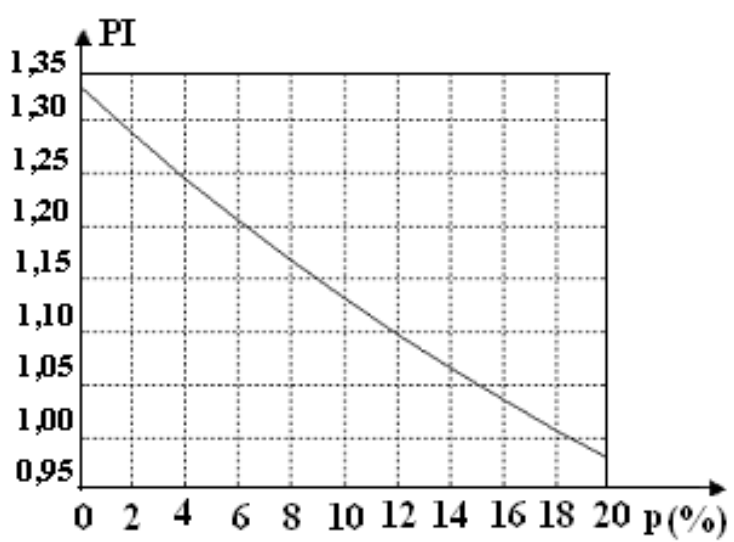

Рис. 3. Графік показника РI

Рис. 2 дозволяє встановити ще один показник - внутрішню норму прибутковості IRR (Internal Rate Of Return), що оцінює рівень ефективності 
інвестиційного проекту. Як видно 3 рис. 2, показник IRR для аналізованого варіанта становить близько $18 \%$. Більш точне обчислення показника IRR виконано за допомогою програми $S M F \_P V$ і склало $18,53 \%$ (розбіжність 3 результатом, наведеними в роботі [3] становить $2,9 \%$ ). Показники $N P V$, PI і IRR застосовуються для комплексної оцінки ефективності інвестиційних проектів.

\section{Висновки та перспектива подальшої роботи за даним напрямком}

Simulink $\epsilon$ найбільш популярним інструментом для проектування і аналізу систем управління, цифрової обробки даних і інших задач моделювання. Він може бути також використаний для аналізу динаміки економічних і фінансових прогнозів. Наведені результати свідчать про доцільність застосування програмного комплексу Matlab/Simulink для оптимізації проектів фінансового менеджменту судноплавних компаній.

\section{ЛIТЕРАТУРА}

1. Ануфриев И.Е., Смирнов А.Б., Смирнова Е.Н. МАТЛАБ 7. - СПб.: БХВПетербург, 2005. - 1104 с.

2. Цисарь И.Ф., Нейман В.Г. Компьютерное моделирование экономики. - М.: Диалог-МИФИ, 2002. - 304 с.

3. Лапкина И.А., Павловская Л.А., Болдырева Т.В., Шутенко Т.И. Проектный анализ. Теоретические основы оценки проектов на морском транспорте. Учебн. Пособие / Под общ. ред. И.А. Лапкиной - Одесса: OHMУ, 2008.- 315c.

4. Черных И.В. SIMULINK: среда создания инженерных приложений / Под общ. ред. к. т. н. В.Г. Потемкина. - М.: ДИАЛОГ - МИФИ, 2003.- 496 с.

5. Удолатий В.Б. Применение среды Scilab для решения задач финансового менеджмента / Матеріали науково-технічної конференції «Енергетика судна: експлуатація та ремонт», 26-28 березня 2014 р. Частина II- Одеса: OHMA, 2014. - C. 124-126. 